\title{
Estudio de las imágenes para la Educación de las Artes visuales en los libros de texto en la Educación Secundaria Obligatoria: implicaciones educativas
}

\section{Study of the images for the Visual Arts Education in Secondary Education textbooks: educational implications}

\author{
IDOIA MARCELLAN-BARACE \\ idoia.marcellan@ehu.eus \\ Universidad del País Vasco \\ AinhoA Gómez-Pintado \\ Universidad del País Vasco \\ ainhoa.gomez@ehu.es
}

Recibido: 16 de noviembre de 2013

Aprobado: 13 de enero de 2015

\begin{abstract}
Resumen
En este artículo se presentan los primeros datos obtenidos en la investigación desarrollada para determinar las relaciones existentes entre las artes visuales tradicionales y otras formas de cultura visual más próximas a las experiencias de los jóvenes de secundaria. La hipótesis por la que se inicia esta investigación es que mientras los estudiantes se nutren y conviven principalmente con las imágenes ofrecidas por la cultura mediática sus libros de texto básicamente se refieren a las imágenes del arte más tradicional. La investigación se ha delimitado a una revisión y análisis de los materiales educativos más usuales para la enseñanza de las artes visuales en secundaria. Tras la sistematización y el análisis de las imágenes que aparecen en los libros de texto, se han detectado tres grandes tipos: las artísticas, las de la cultura mediática y otras. Las conclusiones más relevantes señalan que: apenas hay conexiones entre los diferentes tipos de imágenes, que ofrecen una visión muy tradicional del arte y que las imágenes que contienen están muy alejadas de las experiencias de los jóvenes usuarios de los libros.
\end{abstract}

Palabras clave: educación, artes visuales, secundaria, cultura visual.

Marcellan-Barace, I., Gómez-Pintado, A. (2015): Estudio de las imágenes para la Educación de las Artes visuales en los libros de texto en la Educación Secundaria Obligatoria: implicaciones educativas. Arte, Individuo y Sociedad, 27(2) 179-196 


\begin{abstract}
In this paper we present the first data from the research conducted to determine the relationship between traditional visual arts and other forms of visual culture closer to the experiences of high school youth. The hypothesis of this research is that while students are nurtured and live primarily with the images provided by the media culture, their textbooks basically refer to the more traditional art images. The research has been limited to a review and analysis of the most common educational materials for teaching visual arts in high school. After the systematization and analysis of the images appeared in textbooks, we have detected three major types: the artistics, those who belong to media culture and others. The most relevant conclusions indicate that: there are hardly any connections between different types of images, they offer a very traditional view of art and they are far removed from the experiences of young book users. Keywords: visual arts, education, secondary, visual culture.
\end{abstract}

Sumario: 1. Introducción, 2. Metodología de la investigación, 2.1. Selección de los libros a analizar, 2.2. Categorización de las imágenes, 3. Resultados y discusión, 3.1. Sobre los contenidos generales de los libros de texto, 3.2. Sobre el tipo de imágenes que aparecen en los libros, 3.3. Datos que ofrecen sobre el arte, 3.4. Los datos que ofrecen sobre la cultura mediática, 4. Conclusiones, 4.1 Las ideas sobre el arte que construyen, 4.2 Las ideas sobre la cultura mediática que construyen, 4.3. Sobre las relaciones entre las distintas imágenes, 4.4. La lejanía respecto a la vida de los estudiantes, 4.5 Sería interesante... Referencias.

Este artículo recoge resultados de la investigación titulada "Relaciones entre imágenes artísticas y otras prácticas culturales en libros de texto de secundaria en la C.A.V." financiada por la convocatoria de la Universidad del País Vasco, UPV-EHU, Ayudas a la iniciación/ Reincorporación a la Actividad de Investigación, 2011-13. NUPV11/18

\title{
1. Introducción
}

Desde que en 1997 Giroux nos hablara de la existencia de una pedagogía cultural, vehiculada principalmente por las imágenes proporcionadas por los medios de comunicación, ésta no ha hecho más que ampliar sus registros y modos de acercarse a los estudiantes, desde atractivas estéticas, ofreciendo espacios de participación mediante unos modos y temas mucho más próximos a sus experiencias y vivencias. A nivel académico esta cuestión hace tiempo que constituye uno de los temas centrales en los debates posmodernos en la educación de las artes visuales, y está llevando a-una profunda transformación de las propuestas educativas.

Por un lado, se ve necesaria la ampliación del objeto de estudio, limitado tradicionalmente a las grandes obras artísticas de la cultura occidental. Desde estos postulados se propone considerar el estudio de otras producciones culturales sin poner el acento en su excelencia estética, yendo más allá del análisis de cuestiones de forma, categorías estéticas o peculiaridades gestálticas. Por el otro, se propone la revisión de los fundamentos teóricos, epistemológicos y pedagógicos en la educación de las artes visuales. Entre otras propuestas, se insta a cambiar el enfoque de estudio de las producciones culturales tomando como referencia los estudios de cultura visual, que posibilitan utilizar unas metodologías de análisis que amplían las maneras de acercarse a la visión, lo visual y la visualidad. Se entiende además que la cultura visual, independientemente de que tenga categoría artística o no, debería abordarse también en los entornos escolares porque, entre otras cuestiones: reflejan prácticas sociales (Duncum, P., 1996; Hernández, F., 2007), están próximas a la vida de los estudiantes y ejercen gran 
influencia (Freedman, K., 1997), guían comportamientos y aportan creencias y valores (Duncum, P.,1996, 2002; Freedman, K., 2006) (citados en Marcellán, I., 2010).

¿Cómo se está respondiendo en los contextos escolares españoles a esta cuestión? Una preocupación por indagar los ecos de estos debates posmodernos en los entornos educativos ha motivado la investigación que aquí se presenta. A grandes rasgos, se ha tratado de constatar qué reflejo ha tenido en las propuestas educativas escolares el giro propiciado por los estudios de cultura visual, en cuanto a las maneras de ver y visualizar las manifestaciones culturales y la reflexión sobre las mismas.

En concreto se ha puesto el foco en comprobar cómo es la cultura escolar en el ámbito de la educación de las artes visuales y su relación con la cultura mediática en un contexto muy preciso como es una comunidad autónoma del estado español y en algunos de los materiales didácticos que en ella se utilizan, entendiendo que lo ocurre en esta parcela puede ser un reflejo de lo que ocurre en un ámbito más general.

\section{Metodología de la investigación}

\subsection{Selección de los libros a analizar}

Con el fin de detectar cuáles son los libros de texto más utilizados en la asignatura de Artes Plásticas y Cultura Visual en Educación Secundaria Obligatoria (en adelante ESO), la investigación se ha iniciado con un sondeo en centros escolares públicos, concertados y privados de las 3 capitales de una comunidad autónoma española, en la Comunidad Autónoma Vasca (en adelante CAV). Igualmente, se ha optado por delimitar la investigación a los tres primeros cursos de la ESO, dado el carácter obligatorio de la materia en dichos cursos según indica el currículum (EJGV, 2012, 62). Así mismo el hecho de circunscribirse a los libros empleados por el alumnado y no extenderse a aquellos destinados al profesorado, responde, al hecho de que la mayor diferencia entre el libro del profesor y el del alumno radica en los textos explicativos, más desarrollados, que los primeros suelen poseer y no en las imágenes que suelen mostrar. Cierto es que un libro de texto no es suficiente para explicar la complejidad de los procesos de enseñanzaaprendizaje que se dan en los contextos escolares, de las relaciones que se establecen entre los contenidos, el profesorado y el alumnado, pero sí que reflejan una manera de entender esos procesos, de aquello que se debe aprender y cómo (López, J.T., Mora, M.D., 2001). Por ello el análisis de los mismos deja entrever qué idea de educación de las artes visuales están manejando, qué concepciones sobre las diversas manifestaciones culturales presentan y qué relaciones plantean entre ellas.

Dicho sondeo aportó unos primeros datos que demostraron que el 53,9\% de los centros escolares de la CAV consultados utiliza libro texto en las asignaturas del ámbito de la educación de las artes visuales, mientras que un porcentaje ligeramente inferior $(46,51 \%)$ no hace uso de ellos. No obstante, es conveniente constatar que el hecho de que los centros respondan de manera negativa a la cuestión de la utilización de los libros de texto no significa que no los usen de manera parcial. Muchos de los encuestados confirman que emplean diversas publicaciones didácticas para la realización de materiales propios o que seleccionan parte de los mismos para ser distribuidos en forma de fotocopias entre el alumnado.

A través del escrutinio realizado se pudo constatar que el porcentaje de utilización de las publicaciones variaba ostensiblemente (Fig.1), destacando por su empleo mayoritario 
(40\%) los publicados por la editorial SM, tanto en la versión en lengua castellana como en la vasca (lengua cooficial en la comunidad objeto de la investigación), correspondientes a los niveles I y II. En segundo lugar aparecían los pertenecientes a la editorial Santillana (24\%), también en este caso concernientes a los dos niveles e idiomas, y en tercer lugar la editorial Anaya (con un 21\%). En este último caso es de resaltar el hecho de que el libro de texto utilizado de manera más amplia es el de la versión en castellano $(16 \%)$, mientras que su versión en euskera alcanza únicamente un 5\%, el mismo porcentaje que el resto de los ejemplares aparecidos en la encuesta.

\begin{tabular}{|c|c|c|c|}
\hline Título & Editorial & Idioma & $\%$ uso \\
\hline $\begin{array}{l}\text { Educación Plástica y Visual I y II/ } \\
\text { Plastika eta Ikus-hezkuntza I eta II }\end{array}$ & SM/ Editorial Ikasmina-SM & $\begin{array}{l}\text { Castellano y } \\
\text { euskera }\end{array}$ & $40 \%$ \\
\hline $\begin{array}{l}\text { Serie Galería. Propuestas para la } \\
\text { adquisición de la competencia de } \\
\text { Cultural y artística } 1 \text { y } 2 \text { / Ikusmira } \\
\text { saila. Giza eta arte kulturarako } \\
\text { gaitasuna lortzeko1 }\end{array}$ & $\begin{array}{l}\text { Santillana Educación, S.L/ } \\
\text { Editorial Zubia-Santillana }\end{array}$ & $\begin{array}{l}\text { Castellano y } \\
\text { euskera }\end{array}$ & $24 \%$ \\
\hline Cuadernos de plástica & Editorial Anaya & Castellano & $16 \%$ \\
\hline Plastika koadernoa & Editorial Anaya-Haritza & Euskera & $5 \%$ \\
\hline Arts and Crafts & $\begin{array}{l}\text { Editorial McGraw- Hill, } \\
\text { Interamericana de España } \\
\text { S.L }\end{array}$ & Inglés & $5 \%$ \\
\hline Educación Plástica y Visual & Editorial Donostiarra & Castellano & $5 \%$ \\
\hline $\begin{array}{l}\text { Observar, interpretar, expresar. } \\
\text { Educación plástica visual }\end{array}$ & Editorial Sandoval & Castellano & $5 \%$ \\
\hline
\end{tabular}

Figura 1. Listado de libros utilizados en los centros.

Araízde los datos obtenidos se ha estimado centrar la investigación en las publicaciones correspondientes a las 3 grandes editoriales del estado español: SM, Santillana y Anaya (con sus corresponsalías para las versiones en vasco), dada la escasa presencia del resto.

\subsection{Categorización de las imágenes}

Con el fin de responder a una de las cuestiones principales de esta investigación como es la de visibilizar la relación entre las imágenes artísticas y las de la cultura mediática se ha procedido a la sistematización y clasificación de las imágenes contenidas en los textos escolares. Se ha confeccionando una base de datos mediante el programa filemaker y se ha detectado que las imágenes corresponden a 3 grandes bloques: 
Las artísticas: en este bloque se han registrado aquellas que corresponden a una idea canónica del arte y así han sido catalogadas en los propios libros de texto. Asimismo, se ha especificado si son pinturas, esculturas, pinturas, grabados, fotografías, arquitecturas, instalaciones, etc.

Las de la cultura mediática: aquellas producidas por medios de difusión masiva y que están relacionadas con valores compartidos, o las que tienen una presencia social relevante, es decir, que son referentes. En este caso se ha optado por subdividirlas en: publicidad, teleseries, comics, películas, mapas, logotipos...etc.

Otras: imágenes que también pertenecen a la cultura visual pero que adolecen de las características anteriormente citadas, y que explican e ilustran técnicas o procesos, generalmente imágenes de paisajes, animales, objetos y personas.

Además, de cada una de las imágenes, se han registrado otra serie de variables necesarias para la investigación relativas a la autoría de las mismas, la época, la procedencia, la proximidad a culturas juveniles, etc.

Estos instrumentos de análisis se han elaborado tomando como referencia a autores que han realizado investigaciones similares a la que aquí se plantea ya sea por el objeto de sus estudios o por la metodología empleada (Agirre, I, Arriaga, A, Marcellán, I., 2013; Hernández, M., Acaso, M., Merodio De La Colina, I., Moreno, Mª C. C., Nuere, S., Ávila Valdés, N., Antúnez Del Cerro, N., Hernando, A., Zapatero, D., Abad, Ma .J., 2005; Llorente, E., Andrieu, A., Montorio, A., Lekue, P., 200; Cuenca, J.L, 2003).

Se ha de precisar que en el análisis de los datos se ha optado por un planteamiento metodológico general de carácter cualitativo, para poder ofrecer así una visión holística y enfocar la investigación a la interpretación del significado de los datos numéricos, ya que las imágenes se han abordado desde la perspectiva de los estudios de cultura visual (Mitchell, W.J.T., 1995; Mirzoeff, N., 1999) que se preocupan, entre otras cuestiones, de estudiar su función social, considerándolas como constructoras de significados, como formas que nutren la subjetividad e identidad.

A continuación se da cuenta de los resultados más relevantes obtenidos de los cruces de diversos datos.

\section{Resultados y discusión}

\subsection{Sobre los contenidos generales de los libros de texto}

De manera previa al análisis de las imágenes presentes en los 5 libros seleccionados, centro de interés de esta investigación, seha considerado interesante resumir los contenidos generales que abordan y esbozar así un panorama general que permita contextualizarlas. Para la exposición de estos datos se ha respetado rigurosamente la terminología utilizada en las publicaciones y únicamente en el caso de los materiales en vasco se ha realizado una traducción empleando los términos más habituales. Seguidamente se muestran los contenidos y la estructura que presentan las publicaciones objeto de la investigación:

Educación plástica y visual I, está compuesto por 9 unidades, mientras que Educación plástica y visual II, ambos de la Editorial ikasmina SM, se divide en 11 unidades didácticas; en ambos casos agrupadas en tres grandes bloques (Fig.2). 


\begin{tabular}{|c|c|}
\hline $\begin{array}{l}\text { Plastika eta Ikus-hezkuntza I IkasMina } \\
\text { SM (PIHSM) }\end{array}$ & Educación Plástica y Visual II (EPVSM) \\
\hline 1) Comunicación visual: & 1) Comunicación visual: \\
\hline $\begin{array}{l}\text { 1. Lenguaje visual, 2. Elementos básicos } \\
\text { de la expresión plástica, } 3 \text {. Color. }\end{array}$ & $\begin{array}{l}\text { 1. Percepción y lectura de imágenes; } 2 \text {. Lenguaje } \\
\text { audiovisual; } 3 \text {. Análisis de las formas. }\end{array}$ \\
\hline 2) Forma y geometría: & 2) Estructura y composición: \\
\hline $\begin{array}{l}\text { 4. Formas, 5.Dibujos geométricos, } \\
\text { 6.Formas poligonales, 7.Formas } \\
\text { simétricas. }\end{array}$ & $\begin{array}{l}\text { 4. Elementos de expresión; } 5 \text {. El color; } 6 \text {. Luz y } \\
\text { volumen; } 7 \text {. La composición. }\end{array}$ \\
\hline 3) Espacio y volumen: & 3) Forma y geometría: \\
\hline $\begin{array}{l}\text { 8. Forma en el espacio, 9.Dibujo } \\
\text { humano. }\end{array}$ & $\begin{array}{l}\text { 8. Dibujo geométrico; } 9 \text {. Proporción y } \\
\text { estructuras modulares; } 10 \text {. Sistemas de } \\
\text { representación; 11. Perspectiva cónica. }\end{array}$ \\
\hline
\end{tabular}

Figura 2. Temarios de los libros analizados de la editorial Ikasmina.

Estructura y contenidos muy similares a los anteriores los encontramos en los libros de la editorial Zubia Santillana (IZS) (Fig.3)

\begin{tabular}{|l|l|}
\hline $\begin{array}{l}\text { Ikusmira Giza eta arte-kulturarako } \\
\text { gaitasuna lortzeko 1, Zubia Santillana (IZS) }\end{array}$ & $\begin{array}{l}\text { Ikusmira Giza eta arte-kulturarako gaitasuna lortzeko 2, } \\
\text { Zubia Santillana (IZS) }\end{array}$ \\
\hline 1. Bases del dibujo figurativo & 1. Dibujo al natural, naturaleza muerta \\
\hline 2.Color & 2. Paisajes e interiores \\
\hline $\begin{array}{l}\text { 3. Expresividad de la línea en } \\
\text { el dibujo }\end{array}$ & 3. Dibujo de animales \\
\hline $\begin{array}{l}\text { 4. Representación del volumen } \\
\text { 5. Igualdad y parecido en los } \\
\text { dibujos }\end{array}$ & 4. Proporción; \\
\hline 6. Composición y ritmo & 6. Ritmo y composición; \\
\hline 7. Dibujos geométricos básicos & 7. Dibujo geométrico; diseño; \\
\hline 8. Representación del espacio & 8. Expresión de objetos tridimensionales en el plano. \\
\hline
\end{tabular}

Figura 3. Temario de los libros analizados de la editorial Zubia-Santillana. 
Por último el Cuaderno de Plástica de la editorial Anaya (CPA) se compone de 9 unidades en las que se tratan los siguientes contenidos: 1. Percepción visual 2.Elementos del lenguaje plástico 3.La forma 4. El color 5.el volumen 6. La perspectiva 7.Estructuras geométricas 8. Dibujo técnico 9. La imagen en el mundo actual.

Como se puede observar los contenidos se repiten de manera constante en los cinco libros. Todos ellos se articulan en torno a los elementos básicos del lenguaje visual (textura, forma, línea, color, luz, volumen...), los modos de representación (composición y ritmo, representación del espacio, dibujo del natural...) y conceptos del dibujo geométrico y técnico, dedicando casi la totalidad de sus unidades a estos temas.

En general, las prácticas propuestas en los materiales didácticos se basan en su gran mayoría en ejercicios de copia, estando presentes en menor grado aquellos que plantean reinterpretaciones y menos aún los de carácter crítico o analítico. Así es que respecto a los usos que se dan de las imágenes, predominan aquellos en los que funcionan como ejemplos de los textos explicativos y de los ejercicios prácticos propuestos, y en menor medida (principalmente en los materiales correspondientes a Educación Plástica y Visual I y II) como planteamiento de un "problema" que el alumnado debe resolver aplicando los conocimientos teóricos adquiridos (por ejemplo: identificar el tipo de luz, directa $o$ indirecta, en una imagen).

Por tanto, con este primer 'mapa' ya se puede intuir el tipo de imágenes que van a aparecer en mayor medida y la función que se les atribuye principalmente. De estas cuestiones se da cuenta a continuación.

\subsection{Sobre el tipo de imágenes que aparecen en los libros}

Entre los 5 libros de texto se han catalogado y analizado un total de 1904 imágenes. Siendo, tal y como ya se apuntaba, unos contenidos principalmente dirigidos al estudio de cuestiones formales y de recreación de modelos dados, el mayor porcentaje de imágenes, un $74 \%$, corresponde a la categoría de 'otras', es decir, aquellas que principalmente explican técnicas o procesos; un $21 \%$ lo constituyen las catalogadas como artísticas y un $5 \%$ las que provienen de la cultura mediática (Fig.4).



Figura 4. Porcentajes de los tipos de imágenes. 
Si bien el foco de la investigación está puesto en las relaciones entre las imágenes artísticas y de la cultura mediática en este apartado se van a referir, dada su gran presencia, algunos de los datos más significativos del gran grupo de imágenes que pertenecen a la categoría de 'otras'. En ellas se ha distinguido entre aquellas que explican procesos y técnicas o dan ejemplos de dibujos las cuales suponen el $82 \%$, las que muestras objetos $8 \%$, paisajes $5 \%$, animales $3 \%$ y personas $2 \%$. Son imágenes en las que no aparece autoría alguna ni ficha, información o datos que las contextualicen de algún modo. Parece coherente puesto que su función principal es explicar procesos y técnicas, o mostrar herramientas y objetos con los que trabajar. Así mismo, este cometido conlleva el hecho de que, salvo el $6 \%$ que son abstractas o presentan un grado medio de abstracción, el resto son figurativas.

Este tipo de imágenes apenas conectan con el entorno cultural de los estudiantes a los que van dirigidas, además de porque la mayoría explican procesos y técnicas porque entre el resto no se han encontrado referencias al entorno vasco, ni en las temáticas de las obras, ni en los artistas...etc. Asimismo, tampoco se han encontrado prácticamente imágenes que se refieran a otras culturas con excepción de 9, de un total de 1403 imágenes, que se refieren a Sudamérica y a Asia, es decir, un $0,6 \%$ del conjunto.

Ahora bien en este grupo de imágenes hay cierta proximidad con los estudiantes ya que en varias de estas imágenes aparecen jóvenes como los que podrían ser usuarios de estos textos realizando diversas acciones como por ejemplo jugar al baloncesto, hacer surf, leyendo, etc. En cualquier caso, éstas tan solo suponen el 3\% del total de este bloque (Fig. 5).

\begin{tabular}{|c|c|c|c|c|}
\hline Imágenes categorizadas co & s: 1403 in & nes $(74 \%$ & l total) & \\
\hline Tema representado & & & & \\
\hline Procesos/técnicas/ejemplos & Objetos & Paisajes & Animales & Personas \\
\hline $82 \%$ & $8 \%$ & $5 \%$ & $3 \%$ & $2 \%$ \\
\hline Abstracción & & & & \\
\hline $6 \%$ & & & & \\
\hline Pertenencia al entorno cultu & & & & \\
\hline $0,14 \%$ & & & & \\
\hline Pertenencia a otras culturas & & & & \\
\hline $0,6 \%$ & & & & \\
\hline Cercanas a los intereses juve & & & & \\
\hline $3 \%$ & & & & \\
\hline
\end{tabular}

Figura 5. Imágenes categorizadas como "Otras”.

\subsection{Datos que ofrecen sobre el arte}

A grandes rasgos, los libros de texto analizados, a través de las 410 obras así catalogadas, presentan una idea de arte centrada exclusivamente en las consideradas como grandes obras de la historia occidental y producidas principalmente por hombres. 
Casi todas las obras aparecen acompañadas por una serie de datos tales como el autor, la fecha de realización de la obra, la técnica empleada, las dimensiones, el lugar dónde está ubicada así como alguna información descriptiva o mediante la que se recalquen aspectos formales. Aunque es cierto que un $16 \%$ del total de las imágenes provenientes del arte canónico no presenta ninguna información.

Como hemos reseñado anteriormente, la gran mayoría de las obras están realizadas por hombres: $95 \%$. Los autores y las obras que más se repiten corresponden a Picasso, Miguel Angel y Miró (9 y 8 obras por cada autor) seguidas por las de Escher, Kandinsky, Vasarely y Velázquez (7 obras por cada uno), de Van Gogh aparecen 6, de Degas, Gaudi, Goya, Hockney, Matisse, Sorolla 5 por cada, Calder, Dali, Fra Angelico, Vermer 4 obras por cada uno y de Bernini, Cezanne, Monet, Gargallo, Greco, Da Vinci, Lichtenteis, Pollock, Rothko aparecen 3 obras por cada uno.

Presentes tan solo en tres de los cinco libros analizados se han encontrado 16 mujeres artistas a las que corresponden el 5\% del total de las obras. Los datos ofrecen una imagen de mujer artista asociada a la historia del arte más reciente ya que no aparece ninguna obra anterior al siglo XIX. Respecto a la técnica empleada en las obras, 10 corresponden al ámbito de la pintura (Carmen Laffon, Kristina Buch, Georgia O'Keeffe, Isabel Rodríguez, Isabel Gutierrez, y Soledad Sevilla), 5 al de la fotografía (Laurie Anderson, Cristina Garcia Rodero, Clara de Baeza, Clara Gangutia y Ouka Leele) y únicamente dos representan el campo de la escultura (Jessica Jorgensen) y de la instalación (Alicia Martín).

En este bloque de imágenes, no solo la presencia masculina es mayoritaria sino también lo son las obras correspondientes a la cultura occidental ya que estas suponen el $97,3 \%$ del total. Únicamente el $2 \%$ de las imágenes halladas pertenecen al arte africano y al procedente de Asia, mientras que un residual $0,7 \%$ se encuentra el sudamericano.

Respecto a la cercanía cultural, el hecho de que dos de las editoriales de los libros analizados ofertan una edición en lengua vasca, puede llevar a pensar que dichas ediciones específicas implican además un acercamiento a referentes culturales vascos. Sin embargo no es así ya que la investigación ha revelado que en las obras artísticas tan solo el $2 \%$ corresponde a autores vascos, por su puesto masculinos: Chillida, Oteiza, Anda, Basterretxea, Ibarrola y el arquitecto navarro Moneo son los únicos que aparecen en alguno de los 5 libros. En cuanto a las representaciones o lugares propios tan solo se encuentra un 3\% de ejemplos.

En relación a la contemporaneidad de las imágenes, la gran mayoría son obras producidas en pleno siglo XX (60\%), sin embargo esta cierta actualidad contrasta con algunas de las características de las obras como, por ejemplo, las técnicas empleadas que corresponden mayoritariamente a los tres campos considerados de manera tradicional como Arte. Más de la mitad de las obras, $58 \%$, pertenecen al ámbito de la pintura, seguidas por la arquitectura $13 \%$, la escultura $12 \%$. Dibujo, diseño y fotografía comparten un $3 \%$, los collages y las instalaciones un $2 \%$, y en unos porcentajes muy bajos se encuentran relieves, grabados, imágenes digitales, serigrafías, retablos y land art. Es reseñable el hecho de que no se ha encontrado ninguna otra manifestación artística de carácter eminentemente más contemporánea como performances, videocreaciones o graffitis. 
Si se atiende a otra característica como es el grado de abstracción, se detecta que en su mayoría son figurativas, $71 \%$, que el $14 \%$ tienen un grado medio de abstracción y un $15 \%$ finalmente está lo constituido por obras abstractas.

Reparando en los motivos representados en las 410 imágenes predominan los considerados tradicionalmente de mayor categoría como son los retratos y personas, 19\%; la arquitectura (con imágenes de planos, detalles o edificios emblemáticos) 13\%; los paisajes y temáticas religiosas y mitológicas, con un $12 \%$ y $11 \%$ respectivamente y los bodegones y naturalezas muertas con un 7\%. En porcentajes menores y poco significativos aparecen motivos geométricos, abstractos y animales. En cualquier caso no se han encontrado temáticas ni motivos especialmente próximos a los intereses o culturas juveniles (Fig. 6).

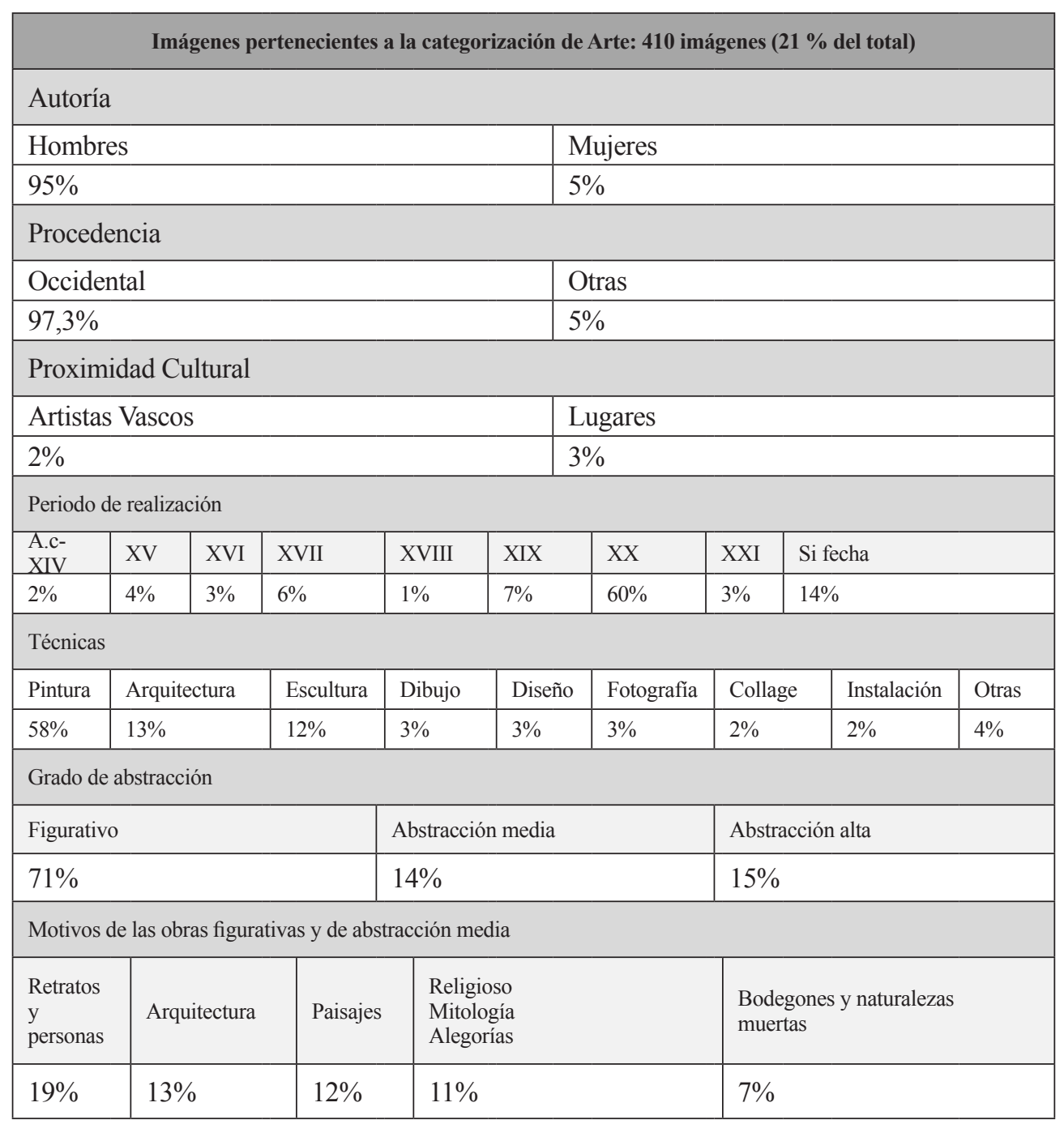

Figura 6. Imágenes categorizadas como "Arte". 


\subsection{Los datos que ofrecen sobre la cultura mediática}

Las imágenes producidas por medios de difusión masiva y que están relacionadas con valores compartidos, las que tienen una presencia social relevante, o que son referentes, tan solo representan el 5\% del total de las imágenes clasificadas en los 5 libros. De este conjunto, un $23 \%$, pertenecen al mundo de la publicidad, y un $18 \%$ lo constituyen imágenes tipo pictogramas vinculadas mayoritariamente con informaciones sobre el tráfico. En una proporción similar, 13\%, aparecen imágenes relacionadas con el cine (carátulas de películas o fotogramas) y con el comic. Imágenes de mapas y elementos de diseño comparten igualmente presencia en un $7 \%$ y el resto de imágenes sobre teatro, televisión, música o danza corresponden a un número irrelevante.

A diferencia de lo que ocurre con las artísticas es significativo el hecho de que en la mayoría de estas imágenes la autoría es anónima; de las 91 imágenes que de los 5 libros se han clasificado en esta categoría tan sólo en 8 ocasiones aparecen autores. Siguiendo la tónica de las imágenes sobre el arte, la mayoría de estos autores son hombres, salvo una fotografía de Lyndsay Addario, y pertenecen al mundo del comic (Ibañez, Quino, Uderzo o Forges). Ni siquiera aquellas imágenes que corresponden a fotogramas de películas muestran datos básicos como el título de la película o autoría.

Respecto a otra serie de datos que ayuden a contextualizar estas imágenes, tales como su procedencia o año de realización, apenas aparecen. En concreto un $85 \%$ de las imágenes no ofrece siquiera el año de su producción. Por el contrario en el 15\% de los casos se especifica que han sido realizadas entre los años 1920 y 2004, si bien tan sólo 4 de estas imágenes un 4,3\% corresponden a la primera década del siglo XXI.

En cuanto a su procedencia todas, salvo una, corresponden a la cultura occidental, al igual que ocurría con las imágenes del arte. (En esta salvedad aparece una imagen que se refiere a la cultura hindú).

Si bien este tipo de imágenes, a diferencia de las artísticas, proceden de un ámbito con el que los jóvenes están más familiarizados, apenas se han encontrado conexiones con sus intereses. Tan solo un $24 \%$ se ha catalogado como cercano a los intereses juveniles; bien por la temática abordada, porque aparecen jóvenes o porque son productos audiovisuales dirigidos al público juvenil. Las más reseñables son las 7 imágenes que reflejan viñetas de cómic, los 4 fotogramas de películas relativamente recientes como Titanic, Avatar, El señor de los anillos o Spiderman o las 5 imágenes publicitarias en las que se alternan anuncios de calzado juvenil o carteles contra la droga. En cualquier caso, la mayoría de las imágenes escogidas en estos libros de texto representan culturas mediáticas propias de una época en la que los estudiantes usuarios de estos libros ni siquiera habían nacido así que los referentes, por ejemplo, de Mortadelo y Filemón o Asterix probablemente les resulten muy ajenos. Lo mismo ocurre con los televisivos, en los que aparecen programas y culebrones de hace 20 años.

En cuanto a los motivos que aparecen en este tipo de imágenes es difícil establecer subcategorías dada la diversidad que abarcan: entre otras encontramos imágenes publicitarias que incitan al consumo de productos, que denuncian cuestiones tales como el maltrato animal, el consumo de drogas o que reivindican el derecho a la igualdad, que representan logotipos de Renfe o museos, pictogramas, mapas varios y un largo etc. difícil de agrupar (Fig. 7). 


\begin{tabular}{|l|l|l|l|l|l|l|}
\hline \multicolumn{6}{|l|}{ Imágenes pertenecientes a la Cultura mediática: 91 imágenes (5\% del total) } \\
\hline Publicidad & Pictogramas & Cine & Comic & Mapas & Diseño & Otras \\
\hline $23 \%$ & $18 \%$ & $13 \%$ & $13 \%$ & $7 \%$ & $7 \%$ & $19 \%$ \\
\hline Autoría anónima & Siglo XX & Siglo XXI \\
\hline $91,2 \% \%$ & $10,7 \%$ & $4,3 \%$ \\
\hline Fecha de realización & Sin fecha & \\
\hline $85 \%$ & Conexiones con los intereses juveniles \\
\hline $24 \%$ &
\end{tabular}

Figura 7. Imágenes categorizadas como "Cultura mediática".

\section{Conclusiones}

Antes de comenzar con las reflexiones a las que los datos expuestos han dado lugar se ha de recordar que esta investigación se aborda desde la perspectiva de los estudios de cultura visual los cuales invitan a intentar desenredar la maraña que pueden suponer unos datos numéricos a la luz de preguntas del tipo: ¿a quién vemos y a quién no vemos?, ¿quién es privilegiado dentro del régimen de especularidad?, ¿qué aspectos del pasado histórico hacen circular en la actualidad representaciones visuales y cuáles no? (Rogoff, I., en Hernández, F., 2007), ¿qué objetos e imágenes son considerados relevantes e importantes para un currículo de artes?, ¿de qué manera las clases de arte ofrecen un lugar para que los estudiantes se impliquen en plantear cuestiones críticas sobre su mundo? (Heisenhauer en Hernandez, F., 2007). Un intento por desvelar alguna de estas preguntas ha dado como resultado el poder iluminar el objetivo principal de esta investigación: determinar las relaciones entre las imágenes artísticas y de la cultura mediática, las conexiones existentes o no entre ellas en los libros de texto más utilizados en la CAV.

\subsection{Las ideas sobre el arte que construyen}

El estudio de los datos llevan a la conclusión de que los cinco libros analizados han seleccionado como exponentes de la cultura artística ejemplos que llevan a una idea de arte asociada a un canon estético occidental y predominantemente clásico tanto por las técnicas que prevalecen (pintura, arquitectura y escultura) como por los motivos principalmente representados anteriormente reseñados: retratos y personas, $19 \%$; arquitecturas, $13 \%$; paisajes , $12 \%$; o temas religiosos, mitológicos y alegorías, $11 \%$. 
El hecho artístico se define por criterios estéticos e históricos hegemónicos y las producciones artísticas se presentan como meras representaciones de la realidad en unos casos o como soluciones a problemas de índole meramente formales (juegos de composiciones, de contrastes de colores...etc.) en otros. En cuanto al enfoque adoptado para trabajar con estas manifestaciones culturales, básicamente, se dirige al aprendizaje de preceptos que rigen la virtud estética de las artes tanto para apreciarlas como para imitarlas en las producciones que los estudiantes deben hacer. Por tanto, estos libros de texto, al igual que detectara Efland (1990 citado en Agirre, I., 2000, 277) en una investigación anterior, también se basan en el estudio de los logros culturales del pasado 'certificados por acreditados expertos' y visibilizan los valores estéticos consagrados.

Estos textos reproducen de manera constante obras de los mismos autores (Picasso, Miguel Angel, Miró, Kandinsky, Vasarely o Velazquez, por ejemplo), destacan su excelencia estética y relegan el arte de otras culturas si bien, tal y como expone Agirre (2000), el arte occidental no es sino una de las manifestaciones de la 'inquietud estética' del género humano y por tanto en el contexto actual en el que en los entornos escolares se concitan estudiantes de distintas culturas la diversificación del objeto de estudio del arte se hace urgente y necesaria.

Es, así mismo, significativa la ausencia de información que ayude a contextualizar las obras, a entenderlas en interacción con cuestiones sociales, políticas y estéticas, dentro de un régimen escópico propio de una época. Las obras artísticas aparecen descontextualizadas de las implicaciones sociales y culturales que también han dado lugar a esas manifestaciones, de las motivaciones que han podido influir en su creación y se obvian las conexiones con otros hechos culturales.

En estas propuestas no se visibiliza el papel de las manifestaciones artísticas en la configuración de creencias, actitudes o imaginarios colectivos que además suelen confluir con el papel que hoy día poseen otras producciones culturales, aunque no sean artísticas.

De este modo, el imaginario de los jóvenes que utilizan estos libros sigue nutriéndose de unos referentes escolares que están construyendo una idea muy pobre y convencional del arte; en ellos se sostiene una idea asociada a la expresión de individualidades, masculinas, occidentales y realizadas en, gran medida, hasta la primera mitad del siglo XX. Una idea de arte asociada al estudio de estilos y corrientes y con propuestas educativas que no posibilitan el análisis, la interpretación y la comprensión de éstas manifestaciones culturales. Y es que, además, cuando los productos culturales, sean artísticos o no, tienen sus principios de construcción en otros epistemes resulta bien difícil comprender sus discursos a través del estudio de técnicas, categorías estéticas tradicionales o peculiaridades gestálticas (Cabrera, R., 2012).

\subsection{Las ideas sobre la cultura mediática que construyen}

Siendo la cultura mediática la que más próxima está de la vida de los estudiantes su presencia en los libros de texto analizados se limita a un escaso 5\%. El valor formativo concedido a este tipo de imágenes, por tanto, es prácticamente nulo y en clarísima desventaja respecto al otorgado a las artísticas. Este hecho resulta un tanto paradójico ante el hecho de que 2 de estos libros en sus propios títulos hacen mención a la cuestión 
'visual' pudiendo parecer que al utilizar esta terminología ampliaran el objeto de estudio. Sin embargo los datos revelan que no es así.

Además las imágenes que presentan están un tanto desfasadas respecto a las experiencias de los usuarios de estos materiales didácticos, un hecho que ya constatábamos por ejemplo en el caso de los comics, al aparecer personajes como Mortadelo y Filemón o Asterix, o en algunos carteles publicitarios en los que se muestran objetos o ropas que poco o nada tienen que ver con referentes actuales. Cierto es que los acelerados cambios que se dan en este aspecto difícilmente puede ser seguidos por las editoriales pero el mayor problema reside en el enfoque que proponen para trabajar con este tipo de imágenes: dirigido únicamente al aprendizaje de los parámetros formales que las constituyen, como pueden ser los colores, las líneas o las tipografías.

Lo más reseñable de este bloque de imágenes, por tanto, es la ausencia, en los libros analizados, de una perspectiva que se fije en la capacidad de estos artefactos de la cultura mediática para construir las subjetividades de todas las personas y especialmente de las más jóvenes a través, eso sí, de sus elaboradas estéticas. De este modo se está obviando su capacidad para generar modelos de comportamiento, creencias o formas de socialización como bien señalaron estudiosos de la cultura visual como Mitchell (1995), Mirzoeff (1999) o Walker y Chaplin (1997) en relación a este tipo de imágenes.

\subsection{Sobre las relaciones entre las distintas imágenes}

El estudio de estas imágenes ha puesto en evidencia una cuestión que se intuía y es que los libros de texto analizados están legitimando unas formas de expresión cultural, las artísticas, que ocupan un lugar preeminente, respecto a las de la cultura mediática. Esta cuestión no está solo corroborada por los datos numéricos, (las artísticas suponen el $21 \%$ del total de las imágenes catalogadas frente al $5 \%$ que constituyen las de la cultura mediática, es decir hay 4 veces más imágenes artísticas que mediáticas), sino que el tratamiento que se da a unas y otras es muy distinto. La información respecto a la autoría, procedencia o año de realización, por ejemplo, con la que aparecen acompañadas las imágenes de la cultura mediática es prácticamente nula, estableciendo así una diferenciación respecto a las artísticas. Una oposición que, en definitiva, revela una desconsideración del valor formativo de las imágenes de la cultura mediática y una relación jerárquica entre ambas; las artísticas son de otra índole puesto que tienen autoría, procedencia y otros datos que les dan cierta entidad reflejando lo socialmente admitido: la supremacía del arte respecto a la cultura mediática en la cultura escolar.

En estos libros de texto no se consideran a todas las formas de manifestación cultural como diferentes respuestas a análogas necesidades de expresión o experiencia estética (Agirre, I., 2000) cuestión que, desde el punto de vista educativo y de la formación personal, sería interesante entenderlas así.

Las propuestas de trabajo que se ofrecen, tanto con unas como con otras imágenes, poseen un diseño muy cerrado, con pocas posibilidades de modificación y actuación por parte de alumnos y profesores. No se proponen relaciones entre las distintas imágenes que trasciendan las conexiones existentes por similitud formal. No hay asociaciones entre las imágenes del arte y la cultura mediática que respondan a problemáticas comunes, ni se establecen puentes de significados entre ellas. Si bien, como recoge Hernández (2007, 49), son varios los autores que han reflexionado al respecto e invitado a: 
-explorar las conexiones entre el arte y la cultura mediática (Marjory y Brent Wilson 2000 y 2003).

-prestar atención a la función de las imágenes en y a través de diferentes sociedades y en diferentes momentos (Chalmers, 1981), perspectiva desde la cual es posible identificar un papel parecido como constructores de narraciones tanto a los cómics, las telenovelas como a las pinturas.

Todo ello con el fin de dotar a los estudiantes de herramientas críticas para estudiar la visualidad humana y aproximarse a las imágenes formulando interrogantes del tipo ¿qué fantasías se nutren de qué imágenes visuales? (Rogoff, 1998 citado en Hernandez, F., 2007), ¿cuál es la función de las imágenes en relación al inconsciente, la memoria, la fantasía y la percepción?, ¿cuál es la relación entre arte y cultura visual?, ¿cómo comunican y significan las imágenes? (Mitchell,W.J.T., 2000).

Mediante estas posiciones se podría trascender y enriquecer una educación en artes visuales limitada a la transmisión de un cuerpo específico de información y valores que pone el foco en el proceso de producción y en el papel preponderante del artista, el cual frecuentemente se presenta aislado de su contexto y del régimen escópico de la sociedad a la que pertenece.

\subsection{La lejanía respecto a la vida de los estudiantes}

Otra de las conclusiones que se derivan del análisis de los datos presentados es la falta de conexión de las imágenes de los libros de texto con las vidas y experiencias de los estudiantes. Esta cuestión se ha dado en las 3 categorías principales en las que se han sistematizado las imágenes de los libros: 'otras', 'artísticas'y 'cultura mediática'.

Son todas ellas imágenes que apenas conectan con las vidas, experiencias y las aspiraciones de los jóvenes que las estudian, ni por las temáticas que abordan ni por los motivos representados ni por las conexiones inexistentes en las propuestas. A este respecto una reciente investigación sobre los saberes que ponen en juego los jóvenes en sus producciones de cultura visual se llegaba a la siguiente conclusión:

Los saberes de la escuela y los agentes que los trasmiten resultan prácticamente irrelevantes a la hora de estimular la actividad productiva de los jóvenes, proporcionar temas o favorecer aprendizajes útiles con tal fin (...), la percepción que tienen con respecto a la relación entre su actividad de productores y la que desarrollan en el instituto o la escuela es de gran lejanía. (Aguirre, Arriaga, Marcellán y otros, 2013:188).

En parte es probable que sea por este desfase encontrado entre sus experiencias y la cultura escolar que los libros de texto como los analizados reflejan.

\subsection{Sería interesante...}

Si bien los libros de texto difícilmente reflejan la complejidad de los aprendizajes y los saberes que se ponen en juego en las aulas sí que dan pinceladas y esbozan los marcos desde los que se empiezan a generar esos aprendizajes. Por tanto, a la vista de los datos obtenidos en esta investigación:

Sería interesante que estos libros completasen su acción formativa con las propuestas realizadas desde los 'estudios visuales' (Bryson, N., Holly, M., Moxey, K., 1991) o la 'educación de la cultura visual' (Duncum, P., 1996, 1997, 2002; 
Hernández, F. 1997; Freedman, K., Stuhr, P., 2004, entre otros). Porque sobre todo posibilitan una aproximación al estudio de las imágenes no como textos cifrados que hay que desvelar o diseccionar sino como condensados de experiencia generadoras de infinidad de interpretaciones. Es decir, como la materialización estética de todo un sistema de creencias, valores, formas, proyectos o sensibilidades individuales y colectivas (Agirre, I., 2000).

Entender así la obra de arte conlleva trasladar el centro de interés desde el artefacto mismo a la actividad experiencial a través de la cual ha sido creado y es percibido o usado y posibilita ampliar el campo de estudio hacia todos los artefactos generadores de tal tipo de experiencia, provengan éstos de las bellas artes o de la cultura mediática.

Sería interesante cambiar la finalidad educadora de querer transmitir un conocimiento disciplinar con visiones hegemónicas y parciales de lo que constituyen las manifestaciones culturales.

Sería interesante aceptar la invitación señalada por Hernández (2007) a establecer puentes con otras bases epistemológicas, saberes disciplinares, nuevas formas y medios de representación así como utilizar metodologías distintas para la interpretación de la imagen, lo visual y la visualidad, con el fin de propiciar experiencias educativas apasionantes, reflexivas y críticas. Porque limitar la educación de las artes visuales, como hacen los libros de texto objeto de la investigación, a la 'disección' de las diversas manifestaciones culturales haciendo propuestas para identificar los códigos y elementos del lenguaje visual resulta muy pobre e insuficiente para comprender y abordar las actuales producciones culturales sean artísticas o no.

De acuerdo con lo planteado por las posiciones señaladas a lo largo de este artículo sería interesante que las propuestas educativas pusieran el acento en comprender el papel que las manifestaciones culturales poseen como portadoras y mediadoras de discursos, y poder comprender así los mundos sociales y culturales que habitan los estudiantes (Efland, E.A., Freedman, K., Stuhr, P., 2003).

\section{Referencias}

Agirre, I. (2000) Teorías y prácticas en educación artística. Pamplona, Universidad Pública de Navarra. Barcelona: Octaedro.

Agirre, I., Arriaga, A., Marcellán, I., Calvelhe, L., \& Olaiz, I. (2013) ¿Jóvenes productor*s de cultura visual? Reflexiones en torno a los resultados de un cuestionario, en EDARTE, Grupo de investigación (ed.) (2013) Investigar con jóvenes: ¿Qué sabemos de los jóvenes como productores de cultura visual?. Pamplona: Pamiela Edarte UPNA/NUP, 190.

Álvarez, J.M., \& Álvarez, S. (2011) Cuaderno de plástica. Madrid: Anaya.

Alzu, J. L., Herrero, M., \& Nuñez, L. (2010) Ikusmira. Giza eta arte-kulturarako gaitasuna lortzeko 1. Etxebarri: Zubia Santillana.

Bryson, N., Holly, M., \& Moxey, K. (eds.) (1991) Visual theory: Painting and Interpretation. Nueva York: Harper Collins.

Cabrera, R. (2012, septiembre). Cómo indagar cuando el ojo salta el muro, Invisibilidades, revista de pesquisa em educaçao, cultura e artes, $\mathrm{n}^{\circ} 3,9-18$. 
Cuenca, J. Ma . (2003) Análisis de concepciones sobre la enseñanza del patrimonio en la educación obligatoria. Enseñanza de las ciencias sociales: Revista de investigación, $\mathrm{n}^{\circ}$ 2. Ver http://www.raco.cat/index.php/EnsenanzaCS/article/view/126155.

Duncum, P. (1996) From Seurat to Snapshots: What the Visual Arts Could Contribute to Education. Australian Art Education, vol. 19: ${ }^{\circ} 2$.

Duncum, P. (1997). Art Education for New Times. Studies in Art Education, vol. 38: $n^{\circ} 2$.

Duncum, P. (2002) Visual culture arte education: Why, What and how. The international Journal of arte education research, $\mathrm{n}^{\circ} 14,15-22$.

Efland, E. A.; Freedman, K., \& Stuhr, P. (2003). La educación en el arte posmoderno. Barcelona: Paidós Ibérica.

Freedman, K., \& Stuhr, P. (2004). Curriculum change for the $21^{\text {st }}$ century: visual culture in art education, pp. 815-828, en Eisner, E., \& Day, M. (Eds.) Handbook of research and policy in art education. Nueva York: Lawrence Erbalbaum associates.

EJGV, Departamento de Educación, Universidades e Investigación (2012). Decretos curriculares para la Educación Básica y Bachiller en la Comunidad Autónoma del País Vasco, p.62. Ver http://www.hezkuntza.ejgv.euskadi.net/r43-5473/es/ contenidos/informacion/dia2/es_2023/adjuntos/decretos_curriculares/dc_educ_ basic_c.pdf.

Giroux, $\overline{\mathrm{H}}$. (1997) Trabajadores culturales y politicas educativas. Barcelona: Paidós.

Hernández, F. (1997) Cultura visual y educación. Sevilla: MCEP.

Hernández, F. (2007) Espigador@s de la cultura visual. Otra narrativa para la educación de las artes visuales. Barcelona: Octaedro.

Hernández, M., Acaso, M., Merodio De La Colina, I., Moreno, Mª C., Nuere, S., Ávila Valdés, N., Antúnez Del Cerro, N., Hernando, A., Zapatero, D., \& Abad, M ${ }^{\mathrm{a} . J}$. (2005). ICON (Iconoteca online), En II Jornada Campus Virtual UCM: cómo integrar investigación y docencia en el CV-UCM. Madrid: Editorial Complutense, 297-300.

López, J.T., \& Mora, M.D. (2001). Los materiales curriculares, un debate abierto, pp. 271-282, en Pozuelo, F.J., \& Travé, G. Entre pupitres. Razones e instrumentos para un nuevo marco educativo. Huelva: Publicaciones de las Universidad de Huelva.

Llorente, E., Andrieu, A., Montorio, A., \& Lekue, P. (2002) Análisis de los libros de texto de Educación Visual y plástica de educación primaria, Revista de Psicodidáctica, $\mathrm{n}^{\circ}$ 14. Vitoria-Gasteiz: UPV-EHU.

Marcellán, I. (2010). Consideraciones sobre las imágenes mediáticas en la educación artística: un referente para la educomunicación, Revista Iberoamericana de Educación, n52, 81-93.

Mirzoeff, N. (2003) Una introducción a la cultura visual. Barcelona: Paidós.

Mitchell, W. J. T. (1995) Interdisciplinary and Visual Culture, The Art Bulletin, vol. $77: \mathrm{n}^{\circ} 4$.

Rodríguez, I., Soler, I., \& Basurco, E. (2008) Educación Plástica y Visual II. Madrid: Editorial SM.

Rodríguez, I., Soler, I., \& Basurco, E. (2010) Plastika eta Ikus-Hezkuntza I. Madrid: Editorial SM, Ikasmina. 
Redal, E.J., Santxo, J. (2010) Ikusmira. Giza eta arte-kulturarako gaitasuna lortzeko 2. Etxebarri: Zubia Santillana.

Walker, J., \& Chaplin, S. (2002) Una introducción a la cultura visual. Barcelona: Octaedro. 